\title{
EL TRATAMIENTO DE LA VIOLENCIA EN LOS MEDIOS DE COMUNICACIÓN.
}

\author{
CLEMENTE PENALVA
}

Profesor de Sociología. Universidad de Alicante.

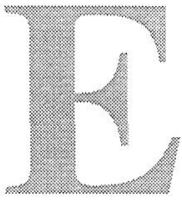

xisten algunas formas de violencia que son menos visibles que la violencia directa: la violencia estructural y la violencia cultural. Cuando se habla de violencia cultural se está haciendo referencia a aquellos aspectos simbólicos de la cultura (sus formas «no materiales», como son el lenguaje y la comunicación) que inciden en la justificación de situaciones violentas, ya tengan éstas un carácter directo o estructural. La violencia cultural, por el hecho de no ser material no es inocua, todo lo contrario, a través de su acción los seres humanos vencen las resistencias a las acciones violentas, adquieren hábitos violentos, apoyan las acciones violentas de las instituciones especializadas o simplemente no reaccionan ante las acciones violentas llevadas a cabo por «otros» (se identifique claramente al agente o no, como ocurre muchas veces en la violencia estructural). Incluso puede llegar a construir algún tipo de consentimiento de aquéllos que sufren directamente la violencia directa (maltrato a mujeres, a niños, a ancianos, por ejemplo, si se interioriza una jerarquía basada en razones de género o edad) o la estructural (justificación de la desigualdad social como fenómeno «natural»).

Los medios de comunicación desempeñan un papel muy importante en la conformación de estas representaciones ideológicas de la violencia, pero no son las únicas instituciones inmersas en este proceso. La violencia de los medios de comunicación (la que aparece en algunas formas de representarla) es una forma más de violencia cultural que es «coherente» con otras formas e instituciones más eficaces de legitimar la violencia directa y la estructural (educación, ciencia, ideología, ejército, empresa, familia, iglesia) con las cuales comparte el papel de agente de socialización, proceso a partir del cual los individuos aprenden a vivir en su sociedad y su cultura e interiorizan valores y normas de comportamiento.

En el cuadro 1 se presentan algunos ejemplos de cómo contribuyen las principales instituciones sociales en la justificación de la violencia. La mayoría opera a nivel inconsciente; algunas, como el ejército, están bastante especializadas -lo exige algo tan difícil de hacer como es el 
enseñar a matar- y otras tienden a contribuir en mayor medida a lo contrario (la escuela y la familia). Muchos educadores se han dedicado a analizar el sistema escolar (los libros de texto, los mecanismos de participación, los sistemas de premios y castigos) para observar cuánto hay de formas pacíficas de resolver conflictos y cuánto hay de todo lo contrario.

Cuadro 1: Algunos ejemplos de cómo opera la justificación de la violencia en la cultura y en las instituciones.

\begin{tabular}{|l|l|}
\hline Ámbito & Mecanismos de legitmización de la violencia. \\
\hline CulturaPopular & Cuentos, refranes, canciones, chistes. \\
\hline Escuela & $\begin{array}{l}\text { Contenidos, no reciprocidad profesor-alumno, segregación, } \\
\text { mano dura. }\end{array}$ \\
\hline Ejército & Patriotismo, culto a las armas, deshumanización del enemigo \\
\hline Empresa & $\begin{array}{l}\text { Diferencias salariales (hombre-mujer; autóctono-inmigran- } \\
\text { te), clasismo. }\end{array}$ \\
\hline Familia & Autoritarismo, menosprecio, transmisión de valores. \\
\hline Medios decomunicación & Estereotipos, desinformación, trivialización de la violencia. \\
\hline Religión & Textos bíblicos (ojo por ojo diente por diente). \\
\hline Ciencia & Deterioro ambiental por razones de progreso. \\
\hline
\end{tabular}

\section{VIOLENCIA REPRESENTADA Y SOBRERREPRESENTA- CIÓN DE LA VIOLENCIA.}

Una vez establecidas estas consideraciones iniciales, con las cuales se pretende no caer en el error de responsabilizar únicamente a los medios de comunicación de la transmisión de conductas y valores violentos, nos ocuparemos a continuación de mostrar las diferentes maneras y mecanismos de legitimación de la violencia que aparecen en los medios. No toda la información contiene este sesgo ni tampoco se puede prescindir de los medios de comunicación. En un mundo donde una gran parte de las relaciones sociales se desenvuelve en el universo mediático, bajo sus diversas formas tecnológicas y de contenidos (información, entretenimiento, conocimiento y formación) los medios adquieren una fenomenal influencia. Tanta que es imposible abarcar en unas pocas páginas todas sus dimensiones y aspectos: incide tanto en la manera de percibir el mundo, como en su funcionamiento económico, cultural y político.

Existen estudios que ofrecen datos bastante expresivos acerca de la representación de la violencia que los medios proporcionan a la audiencia a partir de sus diferentes canales y formas (Sanmartín y otros, 
1998; Clemente y Vidal, 1996). Si analizamos los contenidos de telediarios, cine, series televisivas, dibujos animados, etc., comprobaremos cómo las imágenes, textos, acontecimientos relatados tratan el hecho de la violencia con mucha mayor frecuencia que otros temas. Los contenidos violentos atraviesan todas las manifestaciones mediáticas, desde la información a la formación y el entretenimiento, y también las fronteras políticas y culturales. Los niños y adultos de todo el planeta pueden estar a la última en innovaciones armamentísticas y conocen a Rambo y Terminator. La globalización, pues, alcanza a ídolos massmediáticos poco dados al diálogo y que son fuentes de inspiración de conductas y modelos de imitación (UNESCO, 1998). Por otro lado, el análisis de contenido de los mensajes mediáticos también ha detectado formas habituales de producir prejuicios, como es el hecho de que en gran número de producciones destinadas al cine o la televisión cuyos argumentos están plagados de violencia, los personajes negativos sean representados por minorías (afroamericanos, hispanos) y personas con discapacidad de todo tipo (Greenberg y Brand, 1996). Pero esto último es la cara de ficción de la violencia; también los medios representan la violencia real. En lo relativo a la información, las noticias, ese recurso básico de las democracias que da conocimiento de lo «importante» para una sociedad, son en cierta medida una colección de desastres, sirven la dieta diaria de violencia bajo la forma preferida de imagen gráfica.

Todas las formas de violencia directa que aparecen en el cuadro 1 se muestran continuamente representadas, recreadas en los medios. Si tenemos en cuenta que las soluciones no violentas a los conflictos de cualquier índole (nacionales e internacionales, comunitarios, etc.) son más frecuentes que las soluciones violentas (todas las culturas contienen un amplio repertorio de recursos pacíficos basados en el más simple de ellos, el diálogo, que en algunas sociedades llega a la especificidad y tradición de la diplomacia como disciplina) se deduce que los medios producen una «sobrerrepresentación de la violencia».

Lo primero que conviene hacer en cuanto a esta sobrerrepresentación, es preguntarse el porqué, es decir, cuáles son las razones que explican esta abundancia de contenidos violentos al mismo tiempo que se indaga sobre los efectos de su representación sobre las audiencias (en qué medida nos hace violentos, pero también miedosos o ignorantes). Lo segundo es aportar algo acerca de los remedios existentes para paliar los males producidos por la violencia representada. 


\section{VIOLENCIA Y ENTRETENIMIENTO.}

Parece ser que es el mercado el que explica, por razones de supuesta hegemonía de las preferencias del consumidor, la aplicación del modelo de entretenimiento (dramatización y escenificación de la violencia) a todos los contenidos y géneros mediáticos. El público demanda violencia y no sólo por su espectacularidad (en el caso de la ficción manda la industria de Hollywood con sus efectos especiales), sino también por la afición a la «mirada morbosa» sobre las imágenes o relatos «reales» que ofrecen los medios (desde las escenas bélicas y agresiones, a los cadáveres, y las muertes en directo). Los que han estudiado el fenómeno de la «atracción» por la violencia representada y el morbo hablan de las necesidades de excitación y de emociones fuertes (fenómeno paradójico que mezcla angustia y placer que roza el masoquismo) de personas poco estimuladas o aburridas. Zillmann y Bryant (1996: 603) resumen las razones de esta atracción hacia la violencia en los medios: proporcionan al espectador satisfacción a su curiosidad morbosa, permiten celebrar su sensibilidad emocional al comprobar sus reacciones de rechazo e incitan a la comparación social de su situación con la de los sujetos que aparecen en los medios. En definitiva, permiten a los curiosos morbosos asistir de forma totalmente segura a experiencias peligrosas pero también a las emotivas o ridículas, tal como aparece en los reality y talk shows o en las revistas o programas del corazón donde se mezcla la angustia de la vergüenza ajena y el placer. Desde el punto de vista sociosemiótico, Imbert llama a todo esto «violencia representada» (Imbert: 1992). Se trata de un tipo de violencia simbólica, cuya influencia política y social radica en su capacidad para mostrar las normas sociales y para construir la realidad.

Una vez detectado el impulso de excitación que hace asomarse a la audiencia al morbo de la violencia, todo viene rodado: la publicidad manda y el binomio espectacularidad más dramatización de la violencia incrementa los ingresos. La «economía política» de la violencia mediática señala que la producción de escenas violentas es posible con actores baratos y que los productos son más fácilmente vendibles en mercados internacionales. El esquematismo asociado a este tipo de relatos hace que el lenguaje de la violencia representada sea universal, que en los dibujos animados sea más fácil representar violencia que humor, y que las tramas de sus relatos se reciclen cambiando únicamente los personajes. Las estrategias comerciales van más allá de la mera producción y exposición de los artículos: los dibujos animados se conectan con la industria del video-juego (paradigmático el caso de Pokemon) o los juguetes bélicos en general; y las películas más caras (más impregnadas de efectos especiales de violencia) son mejor distribuidas y promocionadas. 
Se ha estudiado bastante la influencia de la violencia representada en los medios, sobre todo en la TV y recientemente también en los video-juegos de contenido violento. La preocupación principal, debido a que algunas de las últimas generaciones han crecido junto a la televisión, ha sido sobre el efecto de ésta en el proceso de socialización de los niños. Conforme la investigación ha ido avanzando, se ha ido descartando la idea de que la violencia en televisión es violencia en sí misma (con una incidencia directa en la conformación de conductas violentas), para asumir que su poder es reducido y que su principal efecto es incidir en la manera en que la gente percibe la violencia. El más extenso trabajo sobre este tema es el que va llevando a cabo, desde hace décadas el equipo de George Gerbner con su teoría de la «cultivación». Sobre su obra se pueden consultar en castellano la síntesis que el autor hace de su modelo (Gerbner y otros, 1996) y algunos de sus estudios (Roda 1989: 300-365). Gerbner se centra en los efectos a largo plazo, más intensos y difíciles de detectar, asumiendo que la televisión constituye una de las principales fuentes de socialización. Los efectos en este sentido son paulatinos y acumulativos, estableciendo en la audiencia unas pautas estables de selección de contenidos y determinando con relación a éstos conductas, actitudes y prejuicios. Las conclusiones sobre este «efecto de cultivo» son en cierta manera complementarias con las de la teoría del «aprendizaje social» de Bandura. Éste dice que el ser humano aprende nuevas conductas a partir de la observación de otros seres humanos, sobre todo a partir de modelos atractivos. Al producirse la identificación (algo en lo que se esfuerzan los contenidos de los medios) con determinados personajes reales o de ficción, el espectador imita la conducta de estos modelos. Esta imitación no se produce de manera automática (a diferencia de las teorías de los efectos donde todo estímulo tiene una respuesta), sino que el sujeto sopesa las consecuencias personales y sociales de los comportamientos. No obstante, ciertos recursos persuasivos (mediáticos y no mediáticos) ayudan a que una conducta reprobable se convierta en aceptable: la reestructuración cognitiva del comportamiento por medio de justificaciones morales y caracterizaciones paliativas es el mecanismo psicológico más efectivo para promover conductas transgresoras (Bandura, 1996: 103). Las tendencias a la deshumanización, demonización de las víctimas (justificaciones morales), los estereotipos sociales sobre ciertos colectivos como inmigrantes, mujeres, ancianos (caracterizaciones paliativas) y la fuerza de la autoridad (prensa y telediarios; «expertos» y políticos) producen el desplazamiento y la difusión de la responsabilidad del individuo.

La investigación que ha dominado los estudios sobre los efectos ha sido de corte positivista, basada en la medición y la cuantificación. A pesar de su enorme esfuerzo, este tipo de investigación empírica no ha 
dado mucha luz sobre los efectos de la violencia en los medios. Son continuas las discrepacias en torno a los resultados (algunos han encontrado efectos beneficiosos, como es el «catártico», según el cual la violencia en la TV o en los video juegos libera la agresividad reprimida y recupera el equilibrio tras haber pasado por experiencias frustrantes) y la metodología (sobre la validez y fiabilidad de las pruebas y el contexto en el cual se realizan). A pesar de las diferentes controversias, la mayoría de los estudios encuentran correlaciones positivas entre agresividad y exposición a contenidos violentos (García Sílberman y Ramos: 1998). Esto se ha de interpretar solamente en términos de probabilidad (cuanta más violencia vea una persona en televisión, más probabilidad hay de que sea violenta) y no implica necesariamente causalidad, es decir, no significa que la televisión cause violencia. Puede haber otro factor que tenga influencia sobre los otros dos, como, por ejemplo, vivir alguna experiencia violenta puede hacer que seas más violento y que te incite a ver más violencia.

Otras perspectivas, como son las englobadas en los «estudios culturales» (Nightingale, 1999) y en los estudios sobre la «mediación» (Orozco, 1992), son menos ambiciosas, en el sentido de que renuncian a buscar obsesivamente las relaciones estadísticas de causa efecto y se centran más en la tarea de descubrir el significado particular que cada receptor da a los mensajes, partiendo de las situaciones concretas en las cuales éstos son recibidos. Resulta ser un modelo más flexible en el cual se afirma que estos significados y sus consecuencias prácticas sólo son accesibles mediante técnicas cualitativas aplicadas sobre el contexto sociocultural en el que los mensajes son decodificados por la audiencia. En este modelo caben tanto la sintonía del receptor con los significados «preferidos» (aquéllos que se detectan en el análisis de contenido de los mensajes y que corresponden a las intenciones del emisor), como los significados negociados, de rechazo o críticos. Aunque estos modelos relativizan la influencia de los medios no evitan partir en todos sus estudios de su enorme poder ideológico y conformador de opiniones y conductas. Pero el hecho de considerar las conductas resistentes y las lecturas de rechazo como posibles añade un matiz optimista a las conclusiones de otras perspectivas, y eso es muy alentador para los que abogan por difundir mediante la educación la mirada crítica del espectador sobre de la violencia mediática (algunos lugares dentro de la red de centros dedicados a esta difusión aparecen al final del capítulo).

Un efecto bastante claro es el de la habituación a la violencia mediática. Tras muchas décadas de continua exposición se produce una habituación a los contenidos violentos por parte de la audiencia. Llegado el caso, se puede argumentar que el público consume violencia porque se ha habituado en dosis más o menos grandes a ella, a los contenidos 
ligeros y a la actualización de esquemas cognitivos que le permitan clasificar todo en las simples casillas del bien y del mal y de los estereotipos. Por otro lado, en el caso de la televisión y en nuestro país, la competencia entre cadenas ha dado como resultado la renuncia manifiesta a la programación y producción de contenidos instructivos e informativos, con lo cual, la audiencia, obligada a ver «lo que hay», pierde la disponibilidad de esta oferta. El recurso a ciertos canales de pago que se especializan en este tipo de contenidos refuerza la desigualdad social por la vía de la formación y aumenta el distanciamiento informativo de diferentes estratos sociales.

Aun así, aunque consideremos que los medios dan lo que el público pide, este argumento por sí solo vale para los géneros de entretenimiento, pero no para los de la información y la formación. A no ser que se renuncie a la consideración de los miembros de una sociedad como ciudadanos y se les sustituya por consumidores, la información es un recurso básico de una sociedad democrática, de individuos libres, racionales e instruidos (principio fundamental del significado primigenio de «opinión pública») y la obligación de los medios es no abandonar su papel instructivo y difusor de conocimientos. Más aún, si se trata de medios públicos, los cuales, sin prescindir del entretenimiento, deberían poner más interés en la difusión de espacios culturales e informativos.

\section{LA INFORMACIÓN SOBRE LOS CONFLICTOS INTERNA- CIONALES.}

Se constata, como se indicaba más arriba, el desplazamiento hacia el formato de entretenimiento de los telediarios (con inserción de cortes para la publicidad) y también de los periódicos. La violencia está representada y sobrerrepresentada en la forma que exige la progresiva mercantilización de la información: búsqueda de la respuesta emocional del público a través de la preferencia por la imagen (desastres humanitarios) bajo la «dictadura del tiempo real» (Aguirre, 1999). En la prensa escrita llama la atención la disolución de la «sección en vías de extinción» de los sucesos a lo largo de la extensión de todo espacio informativo; la violencia se «representa» en todos los contenidos (nacional, internacional, local, cultura, sociedad, etc.), impregna en mayor o menor medida todo acontecimiento narrado en forma de noticia. Las razones por las cuales existe predominio de noticias sobre acontecimientos negativos, independientemente del grado de violencia representada, también ha sido estudiado. Además de los introducidos anteriormente para explicar la atracción del morbo, existe un conjunto de argumentos de carácter sociológico y político. La información sobre 
alteraciones del orden social permite conformar consensos en lo referente a las normas y valores de una sociedad y en consecuencia tiene incidencia en el grado de cohesión de la misma. También se afirma que los medios de comunicación tienden a exagerar el verdadero peligro que determinadas clases o grupos (delincuentes, terroristas) tienen para la sociedad. La consecuencia es que se generan motivos de preocupación -realmente lejanos de los que afectan principalmente a la sociedad- que conducen a buscar la protección del poder establecido. En este país se debería calcular el provecho político que los gobiernos consiguen a partir de la violencia terrorista, sabiendo que su cobertura mediática es muy amplia y que en muchas encuestas aparece como uno de los principales problemas percibidos por los ciudadanos.

Uno de los lugares donde más cobertura se le da a la violencia es en el apartado de noticias internacionales. Casi el $34 \%$ de las noticias que aparecían en las secciones internacionales de la prensa española durante los años 1992 y 1993 trataba de asuntos relacionados con lo militar, y cuando las noticias concernían a más de un país ese porcentaje se elevaba al 54\% (Penalva, 1998). La guerra, el fenómeno violento que más víctimas produce, tiene un gran seguimiento por parte de los medios. El interés es legítimo (si se busca la paz habrá que conocer la violencia) lo que ocurre es que se habla más de violencia que de resolución de conflictos y no se dedica el suficiente interés ni a las raíces de los conflictos ni a las maneras de prevenirlos.

Se observa que en las guerras contemporáneas las relaciones entre poder y medios mantienen algunos elementos que podemos llamar tradicionales (propaganda y control de los medios), pero también aparecen nuevos aspectos relacionados con el desarrollo de las comunicaciones y la globalización. El recurso de los contendientes a estos elementos es diferente según el tipo de conflictos. Puesto que desde la II Guerra Mundial no se conocen conflictos armados a gran escala entre estados centrales, nos encontramos con dos tipos de conflictos según intervengan o no estas naciones.

En la guerra la propaganda es un arma más, es el principal intrumento para legitimar la violencia y sirve para agitar y animar a la población propia, consiguiendo en la mayoría de las ocasiones no sólo su consentimiento sino también su participación activa en la lucha. Igualmente se utiliza para desmoralizar al adversario. Para todo ello se utiliza fundamentalmente la difusión de una visión parcial de la realidad y el falseamiento de la misma. Esto significa que se ha de disponer en la retaguardia de medios afines, y que se han de silenciar (vía censura o represión) los medios que se oponen a la guerra. La propaganda es un viejo recurso que funciona actualizándose sobre nuevos enemigos para justificar intervenciones con mayor o menor intensidad por todo el pla- 
Cuadro 2: Elementos tradicionales y nuevos en la relación entre medios y poder político.

\begin{tabular}{|l|l|l|}
\hline & \multicolumn{2}{|c|}{ Elementos } \\
\hline Conflictos & Tradicionales & Nuevos \\
\hline Centro-Periferia & $\begin{array}{l}\text { Propaganda, control mili- } \\
\text { tar. }\end{array}$ & $\begin{array}{l}\text { Virtualidad, imágenes pseudorea- } \\
\text { les, silenciamiento de la oposición } \\
\text { interna «Guerra humanitaria». }\end{array}$ \\
\hline $\begin{array}{l}\text { Periferia-Periferia } \\
\text { e intraestatales }\end{array}$ & $\begin{array}{l}\text { Propaganda, control de los } \\
\text { medios, represión de la } \\
\text { oposición interna. }\end{array}$ & $\begin{array}{l}\text { Opinión pública internacional, sen- } \\
\text { sibilización, coacción sobre corres- } \\
\text { ponsales y reporteros gráficos, } \\
\text { efecto CNN. }\end{array}$ \\
\hline
\end{tabular}

neta. Tras la derrota de la amenaza roja, tras el fin de la guerra fría, aparecen nuevos términos en el discurso «defensivo» de Occidente: fundamentalismo y terrorismo internacional para Irán y Argelia; narcoterrorismo para Centroamérica o el más reciente «narcocomunismo» de Colombia (Giordano, 2000).

Estas prácticas propagandísticas han obtenido bastante éxito en muchas de las guerras del siglo XX, pero algunas cosas han cambiado en las últimas décadas. En lo relativo a las intervenciones de los países centrales en países de la periferia las poblaciones son ya menos sensibles a la propaganda, han tomado mayor conciencia de la bondad de las soluciones pacíficas y muchos países han avanzado bastante en cuanto a libertades y derechos de sus ciudadanos. Con ello, no se quiere decir que la propaganda y el control hayan desaparecido, sino todo lo contrario, éstas adquieren un matiz distinto. Con respecto al control en las relaciones entre medios y poder político hay un antes y un después de la Guerra de Vietnam. Ignacio Ramonet (1998: 169-188) ofrece un repaso a la historia del tratamiento periodístico de la guerra y recalca este hecho. Las intervenciones de EEUU desde entonces intentan evitar por todos los medios dos cosas: la libre circulación de periodistas y las bajas de sus propias fuerzas. El primer «experimento» de este nuevo modelo lo llevaron a cabo los británicos en la Guerra de las Malvinas y llegó a su máxima expresión en La Guerra del Golfo (Hussein como adversario poderoso y maligno, control de los periodistas para «asegurar» su protección, provisión de información gráfica, exposición exclusiva de las víctimas del enemigo, agotamiento de las vías diplomáticas) pasando previamente por Granada y Panamá.

Otros nuevos recursos de la propaganda son resultado de la incorporación de nuevos avances tecnológicos. Las imágenes y la inmediatez mandan sobre las crónicas, con lo cual no se dispone ni de tiempo ni de espacio para la interpretación de los corresponsales y la iniciativa informativa puede ser tomada, gracias a los «juegos de guerra» (imá- 
genes del armamento, trayectorias de misiles), por control militar. Las imágenes gustan e impactan al público, pero reducen la comprensión del fenómeno y pueden ser objeto de manipulación o descontextualización.

Escarmentados de lo ocurrido en la Guerra del Golfo, en la Guerra de Kosovo los medios y sus periodistas tomaron algunas precauciones (Sahagún: 2000). No obstante, algunos de estos elementos caracterizaron su cobertura: la mayor parte de las informaciones partía de Bruselas, no cesaban de emitirse imágenes de las víctimas de una parte (refugiados albanokosovares); se produjo, de nuevo, la demonización del enemigo serbio y su personalización en la figura de Milosevic. En definitiva, otra vez se asistió a la producción de un esquema de oposiciones entre el bien y el mal, en el cual las imágenes y relatos de las acciones de la OTAN apenas hablaban de las víctimas que producían, mientras que de las acciones de las fuerzas contrarias se mostraba exclusivamente a las víctimas (Penalva y Mateo: 2000). Por otro lado, los medios informaron poco sobre los movimientos contrarios a la intervención de la OTAN, al mismo tiempo que se presentó a los verdes alemanes (contrarios a ésta según sus principios pacifistas) en una actitud violenta (lanzando un objeto sobre un ministro de su propio partido). Además, algunos medios españoles no enviaron a ningún corresponsal, otros los reemplazaron por periodistas «más críticos» con Belgrado y el gobierno prohibió hacer declaraciones a los militares (Sahagún, 2000: 20).

En cuanto a los conflictos en los países periféricos (de carácter básicamente intraestatal), los medios locales han servido como elementos de agitación por parte de los movimientos enfrentados exarcerbando las diferencias étnicas (Seaton, 2000) y los medios extranjeros han sido utilizados por las fuerzas locales (para movilizar a la opinión pública internacional) y por los gobiernos centrales (para conseguir apoyo político de los ciudadanos). Una característica central de la cobertura de este tipo de conflictos es la apelación al humanitarismo: los medios, mostrando a los damnificados y refugiados de los desastres producidos por la guerra o por fenómenos naturales, tocan la sensibilidad de la opinión pública y ésta presiona a los gobiernos para que actúen. Se intuye en los últimos tiempos, en la política internacional, una inversión en la dirección de la influencia entre medios y poder político, en el sentido de que los medios pueden marcar la «agenda» (lo que es importante para un país) exterior de los gobiernos. A esto se le ha llamado «efecto CNN» 0 «diplomacia del audímentro» (Fisas, 1998) y habría provocado, entre otras, las intervenciones de la OTAN en Bosnia y Kosovo, y la de Estados Unidos en Somalia.

Para algunos, este efecto es demasiado exagerado y sólo ha podido 
funcionar en algunas situaciones excepcionales o cuando se dan condiciones favorables, como son, entre otras: la existencia de intereses nacionales, las posibilidades previstas de éxito y la oportunidad para conseguir lucimiento político (Fisas, 1998: 70-71). De hecho, en muchas zonas de emergencia no se ha intervenido a pesar de su cobertura mediática (Chechenia, Liberia, Palestina, Kurdistán, etc). Jakobsen (2000), sin embargo, considera que no se ha prestado interés a los efectos «invisibles e indirectos» del impacto de los medios sobre las acciones gubernamentales. Los grandes despliegues mediáticos provocan distorsiones sobre la realidad de los conflictos y alteraciones en las acciones gubernamentales y de las organizaciones no gubernamentales que se desarrollan en las zonas de emergencia y en otras zonas «olvidadas». Estos efectos indirectos serían el provocar intervenciones rápidas y más caras, sin planificación, desviar las acciones de las ONG, canalizar los fondos hacia acciones rápidas en detrimento de los destinados a prevención en otras zonas y crear esfuerzos en las partes enfrentadas para incrementar la propaganda.

Una de las consecuencias del efecto CNN, en su afán por buscar y mostrar imágenes de impacto, es que no se atiende a las raíces económicas, sociopolíticas y culturales de los conflictos. La distorsión producida priva a la audiencia del conocimiento del contexto y acaba quedándose solamente con la imagen de sociedades irracionales y con el sentimiento humanitario de compasión por las víctimas. Los esfuerzos de las organizaciones mediáticas para enviar recursos hacia las zonas calientes ocasiona que el público se vea privado de información sobre otras zonas que están en situaciones de pre y postconflicto.

Los países en vías de desarrollo no tienen presencia ni siquiera de manera intermitente en los medios de comunicación y únicamente reciben cobertura cuando se producen acontecimientos de impacto. Una crisis puede ser cubierta durante tres o cuatro días; si no se producen nuevas imágenes, el país queda de nuevo relegado. Las desigualdades en la cobertura entre países ricos y pobres son muy grandes, de tal manera que el público puede percibir ciertas estructuras de los países desarrollados pero sólo información discontinua y coyuntural de los países en desarrollo (Penalva, 1999). En todo caso, la información disponible refuerza los estereotipos occidentales sobre estas sociedades (Antón, 2000) y desvía la atención y los recursos reivindicativos de los públicos hacia las manifestaciones más impactantes de los conflictos. No se da conocimiento sobre lo latente, de lo cual también se pueden encontrar señales, ni se explican las verdaderas raíces de la violencia directa que en muchos casos se encuentran en la pobreza y ésta en las relaciones de dependencia Norte-Sur. A la invisibilidad de estos procesos denomina Golding (1981) «dimensiones ausentes» de la noticia y 
provocan que el público no perciba las diferencias entre las intervenciones para el control político y económico de las verdaderamente humanitarias.

Un ejemplo claro de distorsión, en parte provocado por el fin de la guerra fría y el surgimiento de conflictos interestatales, es la caracterización de estos conflictos exclusivamente como étnicos. El etiquetamiento es uno de los principales recursos de la persuasión y de la violencia cultural, y precisamente los motivos étnicos, en contraste con los políticos, económicos, sociales o históricos, tienen mayor probabilidad de ser percibidos como irracionales por parte del público (Seaton, 2000), Si sumamos los conflictos «étnicos» con los provocados por el «fundamentalismo» musulmán (vasto territorio el que ocupa el Islam) o de cualquier otra confesión no cristiana, resulta que la unidimensionalidad en el análisis causal de los conflictos ha sido característico en mayor o menor grado en las coberturas de casi todas las crisis en la última década. Un nuevo análisis sobre las noticias internacionales recogidas para el estudio anteriormente citado (Penalva, 1998) muestra la diferente relación entre lo militar y lo cultural (entre sus elementos de violencia y etnicidad) según se esté tratando de buenas o malas noticias. Los conflictos armados se relacionan fundamentalmente con los aspectos relacionados con lo cultural (alienación) en una proporción tres veces mayor que con aspectos económicos (miseria).

Tabla 1: Frecuencia y porcentaje de noticias en las que se vincula lo militar con otras categorías.

\begin{tabular}{|l|r|r|l|c|c|}
\hline & \multicolumn{2}{|c|}{ Violencia } & & \multicolumn{2}{c|}{ Seguridad } \\
\hline & $\mathrm{n}^{\circ}$ & $\%$ & & $\mathrm{n}^{\circ}$ & $\%$ \\
\hline Alienación & 40 & $14,8 \%$ & Identidad & 10 & $3,9 \%$ \\
\hline Represión & 36 & $13,4 \%$ & Libertad & 23 & $8,9 \%$ \\
\hline Miseria & 14 & $5,2 \%$ & Bienestar & 22 & $8,5 \%$ \\
\hline Sólo Violencia & 179 & $65,4 \%$ & Sólo seguridad & 202 & $78,6 \%$ \\
\hline Total & 269 & $100 \%$ & Total & 257 & $100 \%$ \\
\hline
\end{tabular}

Estos datos se refieren a la prensa escrita. Sospechamos que, en otros medios, donde el sensacionalismo y la espectacularidad son más fáciles de expresar mediante la información icónica, la percepción de irracionalidad de las sociedades en conflicto es mayor. La televisión, en cualquiera de las formas del efecto CNN, ha provocado despertar el humanitarismo en las audiencias. El hecho de que el humanitarismo se haya visto envuelto en la dinámica mercantil de los medios ha provocado críticas a algunas de sus organizaciones y al sentimiento solidario mismo. Fisas (1998: 74-114) habla de «triángulo de la crisis». Las ONG's necesitan las imágenes sobre desastres y la consecuente res- 
puesta emocional de la audiencia para conseguir recursos y notoriedad: los medios se sirven de las infraestructuras y la información de éstas para cubrir las crisis. Por otro lado, los poderes implicados pueden sacar partido de la difusión mediática de sus medidas y pueden transferir su responsabilidad a las ONG's. Aguirre (1999) aboga, para el tratamiento informativo y la ayuda al Tercer Mundo, por el retorno de la solidaridad política en sustitución del actual humanitarismo apolítico.

La utilización que el mercado o el poder político llega a hacer del humanitarismo (aunque sea la imagen refractada que del mismo dan los medios) puede provocar fenómenos cuando menos «chocantes»: el marketing solidario (si compras el producto $\mathrm{A}$ un porcentaje $\mathrm{X}$ de su valor será destinado a la ayuda al tercer mundo) y la guerra humanitaria (emplear la fuerza armada con mayor capacidad bélica de la historia -léase OTAN en Yugoslavia- con la tarea de destruir gran parte de las principales infraestructuras económicas de un país para «pacificarlo»). Por mucho que las empresas puedan ayudar realmente al desarrollo y que la intervención en Kosovo haya puesto fin a una situación injusta, hasta hace poco los términos de cada una de estas expresiones eran antónimos entre sí.

\section{ALTERNATIVAS PARA PRODUCIR Y LEER CONTENIDOS SOBRE LA VIOLENCIA.}

De la misma manera que no todas las organizaciones humanitarias participan de este juego, tampoco todos los medios, o al menos todos sus profesionales, lo hacen. Ante las crisis internacionales conviene buscar fuentes alternativas de información, contrastar las informaciones a partir de diferentes medios y no dejarse llevar por la «dictadura del tiempo real»: pasado un tiempo se puede conseguir información más fidedigna sobre lo acontecido. Esto supone un notable esfuerzo, justo el que los buenos profesionales de la información realizan con anterioridad a la redacción de sus noticias. Presentamos aquí dos recursos alternativos: uno para la oferta y otro para la demanda, para los productores de contenidos y para los receptores de los mismos.

Existen movimientos alternativos de periodistas, englobados en lo que se ha denominado periodismo de paz (Peace Journalism) que toman conciencia de algunos de estos problemas y del importante papel que ellos pueden ejercer a favor de la resolución de conflictos y de la cultura de paz. Son conscientes de todos los problemas expresados en este capítulo y de muchos más, dado el notable conocimiento adquirido en su práctica profesional. Producto de las conclusiones de una 
reunión internacional sobre periodismo para la paz, mostramos en un cuadro el ejercicio de contraste entre su propuesta de actuación y la que subyace en la práctica del que ellos denominan «periodismo de guerra»:

Cuadro 3: Periodismo de guerra y periodismo para la paz.

\begin{tabular}{|c|c|}
\hline Periodismo de guerra & Periodismo para la paz \\
\hline $\begin{array}{l}\text { Análisis de suma cero. La paz es victoria } \\
\text { y alto el fuego. }\end{array}$ & $\begin{array}{l}\text { Considera que el conflicto tras el cese de } \\
\text { hostilidades puede quedar no resuelto. }\end{array}$ \\
\hline $\begin{array}{l}\text { Busca en la violencia sus propias causas. } \\
\text { Atiende a las raíces estructurales de los } \\
\text { conflictos. }\end{array}$ & $\begin{array}{l}\text { Atiende a las raíces estructurales de los } \\
\text { conflictos. }\end{array}$ \\
\hline $\begin{array}{l}\text { Se concentran en los efectos visibles de la } \\
\text { violencia (víctimas y daños materiales). }\end{array}$ & $\begin{array}{l}\text { Observar también los daños psicológicos, } \\
\text { culturales y sociales. }\end{array}$ \\
\hline $\begin{array}{l}\text { Polarización. Reducción de las partes } \\
\text { implicadas a dos bandos enfrentados. }\end{array}$ & $\begin{array}{l}\text { Considerar otros elementos que no toman } \\
\text { partido por ninguno de los contendientes } \\
\text { y que viven el conflicto. }\end{array}$ \\
\hline $\begin{array}{l}\text { Deshumanización de alguna de las par- } \\
\text { tes. }\end{array}$ & Humanización de todas las partes. \\
\hline $\begin{array}{l}\text { Conducta reactiva (esperar a que la gue- } \\
\text { rra surja). }\end{array}$ & $\begin{array}{l}\text { Proactiva (prevención antes de que ocu- } \\
\text { ra la guerra). }\end{array}$ \\
\hline $\begin{array}{l}\text { Orientado hacia la propaganda (tapar las } \\
\text { verdades de una parte y ayudar difundir } \\
\text { las mentiras de la otra). }\end{array}$ & $\begin{array}{l}\text { Orientado hacia la verdad (desvelar men- } \\
\text { tiras y exponer las verdades de todas las } \\
\text { partes). }\end{array}$ \\
\hline $\begin{array}{l}\text { Centrado en las élites (sufrimiento e ini- } \\
\text { ciativas de paz) }\end{array}$ & $\begin{array}{l}\text { Centrado en el pueblo (sufrimiento e ini- } \\
\text { ciativas de paz) }\end{array}$ \\
\hline
\end{tabular}

Fuente: «The Peace Journalism Option» http://www.gn.apc.org/www.poiesis.org/pjo/pjo.html

\section{Cuadro 4: Enlaces en internet con información sobre periodismo para la paz.}

The Peace Journalism Option: http://www.gn.apc.org/www.poiesis.org/pjo/pjo.html
Peace Journalism and the Kosovo crisis:
http://www.transnational.org/features/2000/LynchPeaceJourn.html
The campaign for Press \& Broadcasting Freedom: http://www.cpbf.demon.co.uk/
Conflict and Peace Forums: http://www.conflictandpeace.org/2med/med_int.html

Por otro lado, en el cuadro siguiente se esbozan algunas pistas para detectar cómo se legitiman algunos tipos de violencia en los medios, así como contenidos alternativos que ayudarían a paliar sus efectos negativos. El cuadro no está acabado, se pueden rellenar con más ejemplos cada una de las casillas; y es posible añadir más categorías (tipos de violencia); incluso se puede duplicar, en el sentido de que pueden 
confeccionarse dos cuadros: uno para los agentes y otro para los destinatarios de cada uno de los tipos de violencia.

\section{Cuadro 5: Representaciones de la violencia en los medios y posibles alternativas.}

\begin{tabular}{|c|c|c|c|}
\hline $\begin{array}{l}\text { Tipos de violen- } \\
\text { cia representada }\end{array}$ & Representaciones & $\begin{array}{l}\text { Formas de violencia } \\
\text { cultural }\end{array}$ & Alternativas \\
\hline Individual & $\begin{array}{l}\text { Violencia gratuita. Deli- } \\
\text { tos contra la propiedad. }\end{array}$ & $\begin{array}{l}\text { Cabeza de turco. Ensal- } \\
\text { zamiento de conductas } \\
\text { ilegales (el Dioni). } \\
\text { Explicaciones exclusiva- } \\
\text { mente psicopatológicas }\end{array}$ & $\begin{array}{l}\text { Mostrar la vida en las cárce- } \\
\text { les, la marginación. Contras- } \\
\text { te entre pobreza y opulencia. } \\
\text { Políticas penitenciarias de } \\
\text { reinserción. }\end{array}$ \\
\hline Grupos (género) & Violación, malos tratos. & $\begin{array}{l}\text { Sexismo, machismo,pu- } \\
\text { blicidad sobre ciertos } \\
\text { productos, la homosexua- } \\
\text { lidad como desviación. }\end{array}$ & $\begin{array}{l}\text { Mostrar cómo los roles sexua- } \\
\text { les son socialmente construi- } \\
\text { dos. Información sobre la ho- } \\
\text { mosexualidad. }\end{array}$ \\
\hline Grupos(edad) & $\begin{array}{l}\text { Tribus urbanas, abusos y } \\
\text { maltrato a menores, des- } \\
\text { trozos en las escuelas }\end{array}$ & $\begin{array}{l}\text { Drogas legales/ilegales, } \\
\text { inmadurez e irresponsa- } \\
\text { bilidad del joven, mayo- } \\
\text { res como improductivos } \\
\text { y como carga social. }\end{array}$ & $\begin{array}{l}\text { Desempleo, labor social y pro- } \\
\text { ductiva de los mayores. Infor- } \\
\text { mación sobre las drogas. }\end{array}$ \\
\hline $\begin{array}{l}\text { Grupos } \\
\text { (minorías) }\end{array}$ & $\begin{array}{l}\text { Pateras, violencia racista, } \\
\text { destrucción de templos. }\end{array}$ & $\begin{array}{l}\text { Estereotipos. } \\
\text { Inmigrante=delincuente. } \\
\text { Etnocentrismo. }\end{array}$ & $\begin{array}{l}\text { Experiencias de coexistencia } \\
\text { multicultural. Vida cotidiana } \\
\text { de los inmigrantes y su papel } \\
\text { económico. Diversidad cultu- } \\
\text { ral. }\end{array}$ \\
\hline Medio ambiente & $\begin{array}{l}\text { Desastres ecológicos, } \\
\text { contaminación. }\end{array}$ & $\begin{array}{l}\text { Inevitabilidad del dete- } \\
\text { rioro ambiental por razo- } \\
\text { nes de progreso. }\end{array}$ & $\begin{array}{l}\text { Modelos altemativos de ener- } \\
\text { gía y transporte; iniciativas } \\
\text { de desarrollo sostenible; } \\
\text { ecología. }\end{array}$ \\
\hline $\begin{array}{l}\text { Sociopolítica } \\
\text { Laboral }\end{array}$ & $\begin{array}{l}\text { Conflicto laboral, huel- } \\
\text { gas, manifestaciones } \\
\text { con resultados de vio- } \\
\text { lencia, piquetes. }\end{array}$ & $\begin{array}{l}\text { Exageración: daños al } \\
\text { consumidor, huelga sal- } \\
\text { vaje. Violencia como ins- } \\
\text { trumento reivindicativo. }\end{array}$ & $\begin{array}{l}\text { Raíces del conflicto social. } \\
\text { Negociación y diálogo. }\end{array}$ \\
\hline $\begin{array}{l}\text { Política } \\
\text { intraestatal }\end{array}$ & $\begin{array}{l}\text { Terrorismo, guerra civil, } \\
\text { represión política, } \\
\text { tortura. }\end{array}$ & $\begin{array}{l}\text { Parcialidad, dramatiza- } \\
\text { ción, propaganda, vio- } \\
\text { lencia como instrumento } \\
\text { político. }\end{array}$ & $\begin{array}{l}\text { Experiencias de diálogo y } \\
\text { negociación. Raíces de los } \\
\text { conflictos. Formas no violen- } \\
\text { tas de reivindicación, princi- } \\
\text { pios del estado de derecho. }\end{array}$ \\
\hline $\begin{array}{l}\text { Política } \\
\text { interestatal }\end{array}$ & Guerra. & $\begin{array}{l}\text { Belicismo, fetichización } \\
\text { y culto a las armas, pa- } \\
\text { triotismo, ineficacia de } \\
\text { la diplomacia. }\end{array}$ & $\begin{array}{l}\text { Centro-periferia, estudios en } \\
\text { profundidad, diálogoy nego- } \\
\text { ciación, éxitos diplomáticos } \\
\text { en la historia. }\end{array}$ \\
\hline
\end{tabular}

Para la lectura crítica de la violencia en los medios se conocen propuestas para ser aplicadas en el ámbito de la educación. La «alfa- 
betización en medios» o media literacy consiste en aplicar precisamente las nuevas tecnologías para conseguir una competencia cultural y capacidad de descodificación de los mensajes que los medios transmiten (Antón, 1998). Algunas de las propuestas se dirigen a la lectura de la violencia en los medios e intentan ayudar a los estudiantes a desarrollar un conocimiento crítico de la naturaleza de los medios, sus técnicas y sus impactos en lo que se refiere a producción de significado y construcción de la realidad.

Cuadro 6: Enlaces en internet sobre educación medios y violencia.

- Center for Media Education:

http://www.cme.org/children/kids_tv/violence.html

- UCLA Center for Communication Policy:

http://www.ccp.ucla.edu/violence.htm

- Proyecto de seguimiento de la violencia en los medios de comunicación: Media Awareness Network. Colección de artículos sobre comunicación y violencia, y estadísticas en:

http://www.reseau-medias.ca/eng/issues/stats/issvio.htm

- Media Education Foundation:

http://www.mediaed.org/enter.html.

Violencia y estereotipos en los medios (homosexualidad, anorexia y bulimia, estereotipos sexuales...) Incluye una colección de artículos del grupo de Gerbner en: http://www.mediaed.org/guides/gerbner/

- Center for Media Literancy: http://www.medialit.org/Violence/indexviol.htm

- Children, Media and Violence del Media Literacy On-Line Project, Universidad de Oregón:

http://interact.uoregon.edu/MediaLit/FA/MLmediaviolence.html\#top

- THE UNESCO GLOBAL STUDY ON MEDIA VIOLENCE:

http://www.fss.uu.nl/mc/nl/onderzoek/unesco.htm

- Leading Edge International Research Group:

http://www.connectcorp.net/ trufax/links/mediaviolence.html.

Enlaces con organizaciones, artículos sobre violencia en los medios

- Conferencia Internacional sobre Violencia, crimen y entretenimiento en los medios, Instituto Australiano de Criminología (1997):

http://www.aic.gov.au/conferences/violence/

\section{BIBLIOGRAFÍA.}

AGUIRRE, M. (1999): «Los medios periodísticos y el espectáculo humanitario» en Unidad de Estudios Humanitarios Los desafios de la acción humanitaria, Barcelona, Icaria, p. 203-226.

ANTÓN, J.A. (1998): «Medios de comunicación, conflictos y Tercer Mundo», 
Las raíces de los conflictos, unidad didáctica 8, Madrid, Observatorio de conflictos, CIP.

BANDURA, A. (1996): «Teoría del aprendizaje social» en en J. Bryant y D. Zillmann (comp.). Los efectos de los medios de comunicación, Barcelona, Paidós.

CERULO, K.A. (1998): Deciphering Violence. The Cognitive Structure of Right and Wrong, New York, Routledge.

CHOMSKY, N. y RAMONET, I. (1996): Cómo nos venden la moto, Barcelona, Icaria.

CLEMENTE, M. y VIDAL, M.A. (1996): Violencia y televisión, Madrid, Nóesis. FISAS, V. (1998): Cultura de paz y gestión de conflictos. Barcelona, Icaria.

GARCÍA SÍLBERMAN, S. y RAMOS, L. (1998): Medios de comunicación y violencia, México, Fondo de Cultura Económica.

GERBNER, G. y otros (1996): «Crecer con la televisión: perspectiva de aculturación» en J. Bryant y D. Zillmann (comp.) Los efectos de los medios de comunicación, Barcelona, Paidós, p. 35-66.

GIORDANO, E. (2000): «Guerra informativa y sociedad televigilada», Voces y Culturas, $\mathrm{n}^{\mathbf{0}} 15,77-88$.

GOLDING, P. (1981): «The missing dimensions. News media and the management of social change» en E. Katz y T. Szecsko (eds.) Mass media and social change, Beverly Hills, Sage, p. 63-81.

GREENBERG, B.S. y BRAND, J.E. (1996): «Minorías y mass media: de los 70 a los 90» en J. Bryant y D. Zillmann (comp.) Los efectos de los medios de comunicación, Barcelona, Paidós, p. 365-422.

IMBERT, G. (1992): Los escenarios de la violencia, Barcelona, Icaria.

JAKOBSEN, P.V. (2000): «Focus on the CNN efect misses the point: the real media impact on conflict management is invisible and indirect», Journal of Peace Research, $\mathrm{n}^{\circ}$ 2, 131-143.

LUCKHAM, R. (1986): La cultura de las armas. Barcelona, Lerna.

MORAGAS, M. (1985) (ed.): Sociología de la comunicación de masas, Barcelona, Gustavo Gili.

NIGHTINGALE, V. (1999): El estudio de las audiencias. El impacto de lo real, Barcelona, Paidós.

OROZCO, G. (1992) (comp.): Hablan los televidentes. Estudios de recepción en varios países. Cuadernos de comunicación y prácticas sociales $n^{\circ} 4$. Universidad Iberoamericana, México, 1992.

PENALVA, C. (1998): Desigualdad entre las naciones y noticias internacionales, Alicante, Publicaciones de la Universidad de Alicante.

PENALVA, C. (2000): «La selección de noticias como indicador de desigualdad entre naciones», Papers, n 59, 1999, p. 155-172.

PENALVA, C. y MATEO, M.A. (2000): «Análisis narrativo y guerra. La cober- 
tura del diario El País sobre el conflicto de Kosovo», Revista Internacional de Sociología (próximo).

RAMONET, I. (1998): La tiranía de la comunicación. Madrid, Debate.

RODA, R. (1989): Medios de comunicación de masas: su influencia en la sociedad y en la cultura contemporáneas, Madrid, CIS-Siglo XXI.

SAHAGÚN, F. (2000): «Los medios de comunicación en la resolución de conflictos», INET Temas, $\mathrm{n}^{\circ}$ 17, (8-20).

SANMARTÍN, J, GRISOLÍA, J.S. y GRISOLÍA, S. (1998) (eds.): Violencia, televisión y cine, Barcelona, Ariel.

SEATON, J. (2000): «Las nuevas guerras 'étnicas' y los medios de comunicación», Voces y Culturas, n 15, 29-60.

STEVENSON, N. (1998): Culturas mediáticas. Teoría social y comunicación masiva. Buenos Aires, Amorrortu.

UNESCO (1998): The UNESCO global study on media violence, París (http:// fss.uu.nl/mc/nl/onderzoek/unesco:htm).

ZILLMANN, D. y BRYANT, J. (1996): «El entretenimiento como efecto de los media» en J. Bryant y D. Zillmann (comp.) Los efectos de los medios de comunicación, Barcelona, Paidós, p. 583-616. 